July 2009

\title{
Erosive Eosinophilic Esophagitis in Rumination Syndrome
}

\author{
Shawn S. Sidhu \\ Northwestern McGaw/NMH/VA-IL, shawnsidhu@yahoo.com \\ James R. Rick \\ Wright Patterson Air Force Base/Wright State University Boonshoft School of Medicine, \\ james.rick@wpafb.af.mil
}

Follow this and additional works at: https://jdc.jefferson.edu/jeffjpsychiatry

Part of the Psychiatry Commons

Let us know how access to this document benefits you

\section{Recommended Citation}

Sidhu, Shawn S. and Rick, James R. (2009) "Erosive Eosinophilic Esophagitis in Rumination Syndrome," Jefferson Journal of Psychiatry. Vol. 22 : Iss. 1 , Article 2.

DOI: https://doi.org/10.29046/JJP.022.1.002

Available at: https://jdc.jefferson.edu/jeffjpsychiatry/vol22/iss1/2

This Article is brought to you for free and open access by the Jefferson Digital Commons. The Jefferson Digital Commons is a service of Thomas Jefferson University's Center for Teaching and Learning (CTL). The Commons is a showcase for Jefferson books and journals, peer-reviewed scholarly publications, unique historical collections from the University archives, and teaching tools. The Jefferson Digital Commons allows researchers and interested readers anywhere in the world to learn about and keep up to date with Jefferson scholarship. This article has been accepted for inclusion in Jefferson Journal of Psychiatry by an authorized administrator of the Jefferson Digital Commons. For more information, please contact: JeffersonDigitalCommons@jefferson.edu. 


\title{
Case Report \\ Erosive Eosinophilic Esophagitis in Rumination Syndrome
}

\author{
$†$ Shawn S Sidhu, $\ddagger$ James R Rick \\ $\dagger$ Northwestern McGaw/NMH/VA-IL $\ddagger$ Pediatric Gastroenterology Division of Wright Patterson \\ Air Force Base of Dayton, $\mathrm{OH}$;
}

\section{INTRODUCTION}

Rumination syndrome involves bringing up partially digested food into the pharynx voluntarily, followed by reswallowing or expelling. ${ }^{1}$ It was discovered in the $17^{\text {th }}$ century ${ }^{2}$; however, knowledge of the disorder has remained sparse until recently. Indeed, the first case of adult rumination in Japan was reported as recently as $2006 .{ }^{3}$ Due to this recent increase in awareness, notions about the disease have remained in a state of constant fluctuation. While first believed to be a disease of neurologically-impaired ${ }^{4}$ children between 3 and 8 months of age ${ }^{5}$, it is now widely recognized as occurring in men and women of all ages and cognitive abilities. ${ }^{6,78}$ Originally rumination was labeled benign ${ }^{9}$; however, it is now known to cause such complications as weight loss, malnutrition, dental erosions, halitosis, electrolyte abnormalities, ${ }^{10}$ abdominal discomfort, weight loss, ${ }^{6}$ choking, aspiration, and pneumonia. ${ }^{11}$ Similarly, while the absence of gastroesophageal reflux disease was an original criterion for the syndrome, ${ }^{12}$ it has been found that many of these patients have evidence of "pathologic gastroesophageal reflux." ${ }^{13}$ Some suggest that thorough upper gastrointestinal workup, such as upper esophageal barium studies and EGD, not be done on children presenting with rumination, despite the presence of abdominal pain or other accompanying gastrointestinal symptoms. ${ }^{6}$ We performed a thorough upper gastrointestinal workup on a patient with concurrent rumination syndrome and heartburn, and were intrigued by the findings.

\section{CASE REPORT}

A 10 year old boy in the fifth grade with anxiety disorder, obsessive-compulsive disorder, and allergic rhinitis was referred to the Department of Pediatric Gastroenterology to evaluate suspected esophageal reflux. History revealed a chronic pattern of post-prandial regurgitation, rechewing, and reswallowing of food and liquids consistent with rumination syndrome of two year duration. He did experience heartburn and noted an "acid-like" sensation in his pharynx even in the absence of food. Remarkably, he was able to willfully suppress and/or aggravate his regurgitation and it occurred up to 2040 times a day. He denied any dysphagia, retching, nausea, chest or abdominal pain. Ranitidine had been started by his Pediatrician with a reduction in the heartburn, but no change in the rumination. His anxiety and obsessive-compulsive disorders were managed by psychotherapy and prozac $20 \mathrm{mg}$ qd. The only other medication was zyrtec $10 \mathrm{mg}$ qd. His general development was normal and academic performance in public school excellent. Family history was significant for maternal history of esophageal reflux and hiatal hernia with subsequent fundoplication. His vital signs were normal and height, weight and body mass index were noted to be at the 20th percentile, 35th percentile and 60th percentile for his age, respectively. Physical exam was normal, though very prominent circumvallate papillae on the posterior aspect of the tongue were noted.

He was started on lansoprazole $15 \mathrm{mg}$ po qd and an upper gastrointestinal series was found to be normal. Because of persistent heartburn and regurgitation, an upper gastrointestinal endoscopy was performed. Interestingly, distal erosive esophagitis and an antral predominant nodular gastritis were found. A mild active gastritis was seen on biopsy with Helicobacter pylori identified by special stains. Campylobacter pylori-like organism (CLO test) rapid urea test was positive. The distal esophageal biopsy showed dense intraepithelial eosinophillic infiltration and basilar hyperplasia (Image 1). The middle and 
upper esophagus were not biopsied secondary to normal endoscopic appearance. He was treated with lansoprazole $15 \mathrm{mg}$ BID and a ten day course of amoxicillin and clarithromycin. Six weeks after the endoscopy, H. pylori fecal antigen test was negative. He was continued on acid suppression, antidepressants, and psychotherapy.

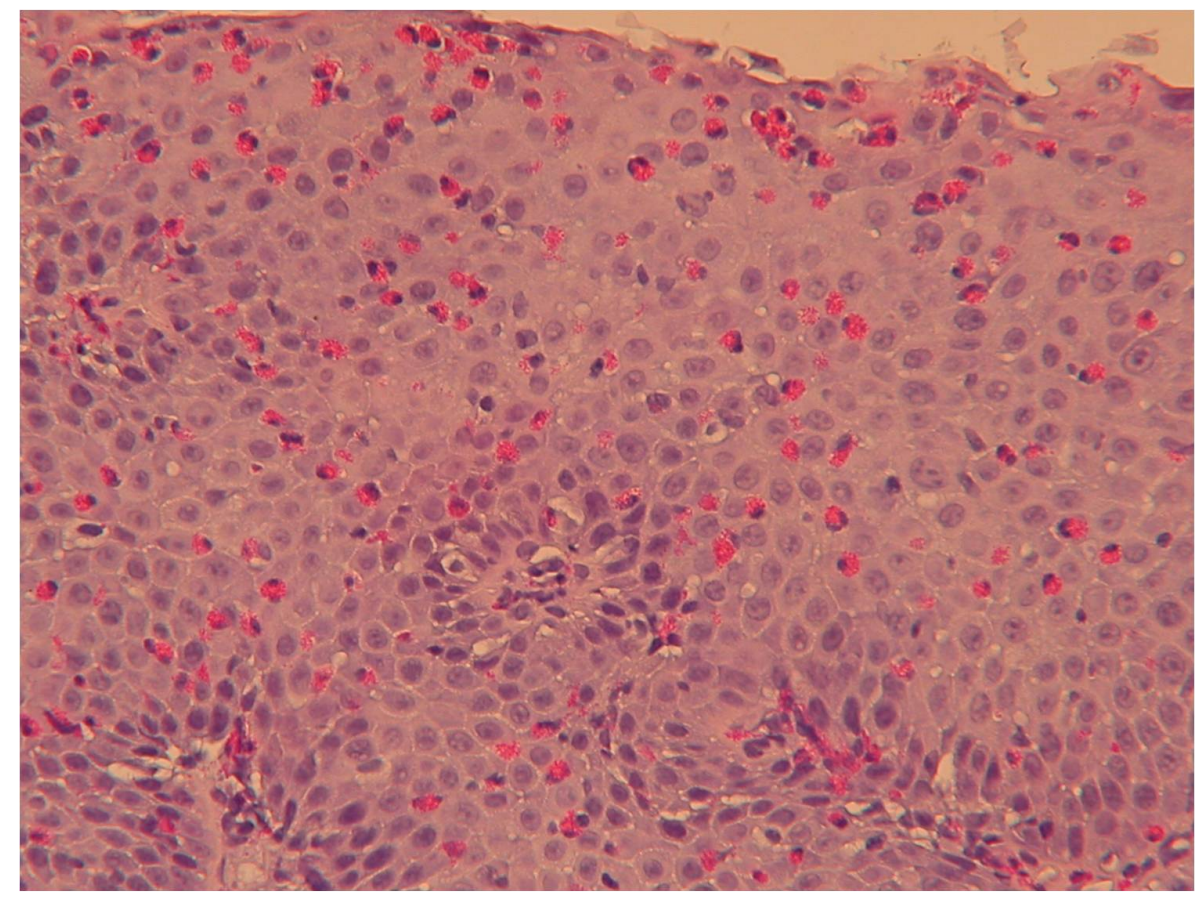

Despite these therapies, breakthrough heartburn, regurgitation and rumination persisted. Four months later, a follow up upper endoscopy was performed. This time his esophagus and gastric mucosa appeared completely normal, with gross resolution of the previous findings. While the middle esophageal biopsy was negative, the distal esophageal biopsy showed squamous epithelium with scattered $(2-4 / \mathrm{hpf})$ intraepithelial eosinophils, a reduction from the prior biopsy. There was no evidence of $H$. pylori. Acid suppression was increased sequentially increased to $30 \mathrm{mg}$ of lansoprazole BID with resolution of his heartburn and acid sensation. His rumination has continued and he is currently being instructed on diaphragmatic breathing with partial success.

\section{DISCUSSION}

Eosinophilic esophagitis is thought to be either reflux-induced or allergic in nature. ${ }^{14}$ Our patient's case was most likely reflux-induced because "gross and histologic esophageal abnormalities normalized following treatment with a PPI, implicating acid reflux as the underlying cause." ${ }^{, 14}$ Yet, the central issue at hand isn't our patient's diagnosis. The novel issue being discussed here is the standard of care in a child presenting with both rumination syndrome and heartburn. The current standard of care in rumination is reassurance and behavioral therapy as a treatment modality. ${ }^{3,13,15,16,17,18,19,20,21,22,23}$ As stated above, upper gastrointestinal barium series and EGD have been deemed noncontributory in patients with rumination syndrome. ${ }^{6}$ Some doubt esophagitis occurs at all patients with rumination, claiming "vomitus contains mainly food, and acid, if present, does not have prolonged contact with the esophageal mucosa." ${ }^{18}$ Clearly, our patient was a ruminator with pathologic erosive esophagitis. Had we adhered to these guidelines, we would've missed a major finding in our patient. Eosinophils in the esophageal mucosa, to any degree, is considered pathologic. ${ }^{24}$ Our effective treatment of his reflux esophagitis could've prevented potentially serious complications of esophagitis, such as ulcers, laryngeal disease, chronic cough, Barrett's esophagus, and esophageal adenocarcinoma. ${ }^{25}$ By no means do we feel that every child with rumination syndrome should receive a thorough upper gastrointestinal workup. Our suggestion is that those with accompanying heartburn be evaluated for their reflux. 


\section{REFERENCES}

1) American Psychiatric Association. Diagnostic and statistical manual of mental disorders. $3^{\text {rd }} \mathrm{ed}$, revised. Washington (DC): American Psychiatric Association; 1987.

2) Kanner L. Historical notes on rumination in man. Med Life 1936;43:27-60.

3) Sugawa T, Fujiwara Y, Okuyama M, et al. Rumination syndrome in an adult with normal intelligence. Nippon Shokakibyo Gakkai Zasshi. 2006 Jun;103(6):631-5.

4) Sullivan PB. Gastrointestinal problems in the neurologically impaired child. Baillieres Clin Gastroenterol. 1997;11(3):529-46.

5) Rasquin-Weber A, Hyman PE, Cucchiara S, et al. Childhood functional gastrointestinal disorders. Gut 1999;45:60-68.

6) Chial HJ, Camilleri M, Willieams DE, et al. Rumination syndrome in children and adolescents: diagnosis, treatment, and prognosis. Pediatrics 2003;111:158-162.

7) Malcolm A, Thumshirn MB, Cmilleri M, et al. Rumination Syndrome. Mayo Clin Proc 1997;72:646-652

8) Olden KW. Rumination Syndrome. Curr Treat Options Gastroenterol 2001;4:351-358.

9) Levine DF, Wingate DL, Pfeffer JM, Butcher P. Habitual rumination: A benign disorder. BMJ 1983;287:255-6.

10) O'Brien MD, Bruce BK, Camilleri M. The rumination syndrome: clinical features rather than manometric diagnosis.

Gastroenterology 1995; 108:1024-1029.

11) Konarski EA, Favell JE. Manual for the Assessment and Treatmetn of Behavior Disorders of People With Mental Retardation. North Carolina: Western Carolina Center Foundation, 1992.

12) Clouse RE, Richter JE, Heading RC, Janssens J, Wilson JA Functional esophageal disorders. Gut 1999;45(suppl 2):1131-1136.

13) Tack J, Talley NJ, Camilleri M, et al. Functional Gastroduodenal Disorders. Gastroenterology 2006;130:1466-1479.

14) Ngo P, Furuta GT, Antonioli DA, et al. Eosinophils in the esophagus-peptic or allergic eosinophilic esophagitis? Case series of three patients with esophageal eosinophilia. Am J Gastroentero 2006;101:1666-1670.

15) Amarnath RP, Abell TL, Malagelada JR. The rumination syndrome in adults. A characteristic manometric pattern. Ann Intern Med 1986;105:513-8.

16) Chitkara DK, Tilburg MV, Whitehead WE, et al. Teaching Diaphragmatic Breathing for Rumination Syndrome. Am J Gastroenterol 2006;101:2449-2452.

17) Johnson WG, Corrigan SA, Crusco AH, Jarell MP. Behavioral assessment and treatment of post-prandial regurgitation. J Clin Gastroenterol 1987;9:679-84.

18) Khan S, Hyman PE, Cocjin J, et al. Rumination syndrome in adolescents. J Pediatr 2000;136:528-31.

19) Oelschlager BK, Chan MM, Eubanks TR, et al. Effective treatment of rumination with nissen fundoplication. J Gastrointest Surg 2002;6:638-644.

20) Parther CM, Litzinger KL, Camilleri M, Thumshirn M, Williams DE. An open trial of cognitive behavioral intervention in the treatment of rumination syndrome [abstract]. Gastroenterology 1997;112:A808

21) Shay SS, Johnson LF, Wong RK, et al. Rumination, heartburn, and daytime gastroesophageal reflux. A case study with mechanisms defined and successfully treated with biofeedback therapy. J Clin Gastroenterol 1986;8:115-126.

22) Smout AJ, Breumelhof R. Voluntary induction of transient lower esophageal sphincter relaxation in an adult patient with rumination syndrome. Am J Gastroenterol 1990;85:1621-5.

23) Sokel BS, Devane SP, Bentovim A, Milla PJ. Self hypnotherapeutic treatment of habitual reflex vomiting. Ach Dis Child 1990;65:626-7.

24) Winter HS, Madara JL, Stafford RJ, et al. Intraepithelial eosinophils: a new diagnostic criterion for reflux esophagitis. Gastroenterology 1982;83:818-23.

25) Featherstone EA. Severe GERD: effective treatment prevents potentially serious complications. JAAPA. 2005 Apr;18(4):259;quiz31-2 